Article

\title{
Serum Calreticulin Is a Negative Biomarker in Patients with Alzheimer's Disease
}

\author{
Qiao Lin ${ }^{1, *}$, Yunpeng Cao ${ }^{2}$ and Jie Gao ${ }^{3}$
}

1 Department of Internal Medicine, the Fourth Affiliated Hospital of China Medical University, Shenyang 110005, China

2 Neural Department of Internal Medicine, the First Affiliated Hospital of China Medical University, Shenyang 110001, China; E-Mail: caoyun2@163.com

3 Department of Anatomy, the First Affiliated Hospital of China Medical University, Shenyang 110001, China; E-Mail: gaojie3@163.com

* Author to whom correspondence should be addressed; E-Mail: qiaolinsy@163.com; Tel.: +86-24-6203-6994; Fax: +86-24-6203-6996.

External Editor: Camile S. Farah

Received: 9 October 2014; in revised form: 3 November 2014 / Accepted: 10 November 2014 / Published: 25 November 2014

\begin{abstract}
Calreticulin is down-regulated in the cortical neurons of patients with Alzheimer's disease (AD) and may be a potential biomarker for the diagnosis of AD. A total of $128 \mathrm{AD}$ patients were randomly recruited from May 2012 to July 2013. The mRNA levels of calreticulin were measured from the serum of tested subjects using real-time quantitative reverse transcriptase-PCR (real-time qRT-PCR). Serum levels of calreticulin were determined by ELISA and Western Blot. Serum levels of calreticulin in $\mathrm{AD}$ patients were significantly lower than those from a healthy group $(p<0.01)$. The baseline characters indicated that sample size, gender, mean age, diabetes and BMI (body mass index) were not major sources of heterogeneity. The serum levels of mRNA and protein of calreticulin were lower in AD patients than those from a healthy group, and negatively associated with the progression of $\mathrm{AD}$ according to CDR scores $(p<0.01)$. Thus, there is a trend toward decreased serum levels of calreticulin in the patients with progression of AD. Serum levels of calreticulin can be a negative biomarker for the diagnosis of AD patients.
\end{abstract}


Keywords: Alzheimer's disease; serum calreticulin; negative biomarker; real-time quantitative reverse transcriptase-PCR; ELISA; western blot

\section{Introduction}

The global prevalence of Alzheimer's disease (AD) has been estimated to be over 24 million, and the number is predicted to be double within two decades [1]. As the population continues to age in the world, the number of people with AD is still increasing, particularly among the elderly population. $\mathrm{AD}$ patients typically have impaired declarative memory [2]. One of the hallmarks of $\mathrm{AD}$ is that amyloid plaques in brain are usually surrounded by neurofibrillary tangles [3]. The etiology of AD remains unknown, but it is more likely to be caused by both genetic and environmental elements. For instance, there is a strong genetic basis for late-onset AD and APOE4 allele has been identified to be associated with risk of $\mathrm{AD}$ [4,5]. Another example, neurons live in an environment of neuronal degeneration in AD patients, which can be partially caused by diverse environmental stressors, such as psychological stress [6], anesthesia [7] and glucose hypometabolism so on [8]. All these stressors can promote tau hyperphosphorylation, amyloid-beta (Abeta) aggregation and oligomerization, which is tightly associated with the pathogenesis of $\mathrm{AD}[9]$.

To define best treatment strategies, early pathological diagnosis is very important for correct and on-time treatment of $\mathrm{AD}$. The neuropathological effects of $\mathrm{AD}$ can be observed using autopsy, but confirming diagnostic and prognostic biomarkers in AD patients is not straightforward [10]. The cerebrospinal fluid (CSF) biomarkers total tau, phosphorylated tau, and 42 amino acid form of Abeta (Abeta42), have enough accuracy for the early diagnosis of AD [11]. Current AD guidelines have recommended that criteria for the diagnosis of $\mathrm{AD}$ should be that the levels of increased phosphorylated tau and total tau, and reduced Abeta42 are measured in CSF [12]. However, a spinal tap is required to get CSF [13]. Furthermore, obtaining biopsies is often invasive and more difficult to conduct. Not all patients like to accept the diagnosis, so researchers are still exploring other effective methods.

Presently, some potential biomarkers for AD are widely reported. For instance, DNA damage is related with the progression of AD. Biomarkers for DNA damage (chitinase and stathmin) are significantly increased in AD patients compared to healthy subjects [14]. Comparatively, a serum biomarker can be measured using a non-invasive method and more patients like to accept it. Therefore, many serum biomarkers for the diagnosis of $\mathrm{AD}$ patients have been exploited such as insulin-like growth factor I (IGF-I). IGF-I can enter mammalian brains and promote clearance of amyloid peptides known to accumulate in the brains of AD patients. Low levels of IGF-I have been observed in AD patients compared to healthy subjects. IGF-I can be developed as a potential biomarker in AD patients [15]. In a further example, one serum protein, activity-dependent neuro-protector homeobox protein (ADNP) is reduced in AD patients compared to healthy subjects [16]. ADNP can maintain cell survival via the modulation of p53 levels [17]. It also protects cerebral cortical neurons against Abeta42, and inhibits Abeta42 aggregation in the brain of AD patients [17]. The serum levels of protein are a direct indicator of $\mathrm{AD}$. ADNP plays a critical role in preventing the progression of $\mathrm{AD}$. 
The recent progresses in the use of $\mathrm{AD}$ biomarkers, which provide strong evidence for the disease, have stimulated the novel research criteria that re-conceptualizes the diagnosis involving both aspects: cognitive changes and structural/biological evidence of AD pathogenesis [18].

Further research of the biology of $\mathrm{AD}$ and improved diagnostic techniques are still critical to develop reliable biomarkers for the diagnosis of $\mathrm{AD}$. Calreticulin is endoplasmic reticulum (ER) resident protein 60, which is encoded by CALR gene. Calreticulin can binds $\mathrm{Ca}^{2+}$ (a second messenger during signal transduction) and render it inactive. Calreticulin also binds misfolded proteins and prevents them from being transferred from ER to Golgi apparatus. More importantly, calreticulin regulates gene transcription via nuclear hormone receptors [19]. Therefore, calreticulin is a multifunctional protein, which involves many physiological activities of cells. A previous report finds that calreticulin is an important protein in human brain, and low levels of calreticulin are observed in the brains of AD patients, suggesting the down-regulation of calreticulin will lead to the pathological processes of $\mathrm{AD}$ [20]. Furthermore, calreticulin is also a cell surface scavenger receptor and can interact with Abeta [21], which is the therapeutic target of AD [22]. All the information suggests that calreticulin is an important biomarker for preventing the development of AD. Here, we explore the possibility for using serum calreticulin as a biomarker to predict the occurrence of AD. This biomarker may contribute to the early diagnosis of $\mathrm{AD}$.

\section{Results and Discussion}

\subsection{Demographic Characters}

Table 1 showed demographic characters of AD patients and healthy subjects. A total of 128 AD patients received medical history and neurological examination (male/female 58/70; mean age of 66.4 years, range 45.4-87.4) (Table 1). All 130 controls were cognitively intact, after receiving medical history and neurological examination (male/female 60/70; mean age of 65.1 years, range 44.1-86.1).

Controls matched AD cases well if considering the effects of sex and age $(p>0.05)$. Previous work finds that $\mathrm{BMI}$ is related with the development of $\mathrm{AD}[23,24]$. To avoid the heterogeneous influence of BMI on our results, the healthy subjects were selected to make sure that there were no significant statistically differences between AD patients and healthy participants $(p>0.05)$ (Table 1). Thus, BMI was not a risk factor of AD patients. Diabetes affects many elderly people in the world, with a great decrease in life quality. Diabetes has been found to affect a brain and to be a contributing risk for the development of AD [25,26]. In the same case, Blood pressure and heart disease have also been reported as risk factors of $\mathrm{AD}$ [27,28]. Furthermore, smoking is associated with a decrease of gray matter density in brain regions, which contributes to the incipient AD [29]. Drinking alcohol also can impair the brain function of individuals and cause dementia and geriatric cognitive disease [30,31]. Individuals with longer education have better cognitive function than those with less education in $\mathrm{AD}$ patients [32,33]. Compared to right handers, left handers reduce the risk of AD [34]. During the recruiting period, all these factors were also carefully considered to avoid heterogeneous effects on final results (Table 1). 
Neuropsychological tests indicated that all AD subjects had MMSE scores $<24$ while all healthy participants had MMSE scores of $>27$. All AD participants had an overall CDR scale of 0.5 or over 0.5 , and none was zero while overall CDR scale of all healthy subjects was zero (Table 1). These results implied that all AD patients had clinical cognitive disorders while all healthy subjects were free of clinical cognitive disorders.

Table 1. Baseline characters of study patients and healthy subjects.

\begin{tabular}{|c|c|c|c|c|}
\hline & $\begin{array}{l}\text { AD Patients } \\
(n=128)\end{array}$ & $\begin{array}{l}\text { Healthy Subjects } \\
\qquad(n=130)\end{array}$ & $\begin{array}{l}\text { Statistical } \\
\text { Value }\end{array}$ & $p$-Value \\
\hline Gender (male/female) & $58 / 70$ & $60 / 70$ & $7.3^{\mathrm{a}}$ & 0.825 \\
\hline Age (years) & $65.4 \pm 21.0$ & $65.1 \pm 21.0$ & $0.21^{\mathrm{b}}$ & 0.933 \\
\hline BMI $\left(\mathrm{kg} / \mathrm{m}^{2}\right)$ & $24.9 \pm 4.8$ & $25.6 \pm 5.1$ & $0.34^{b}$ & 0.900 \\
\hline Diabetes/Non-diabetes & $12 / 116$ & $12 / 118$ & $91.9^{\mathrm{a}}$ & 0.898 \\
\hline $\begin{array}{l}\text { High blood pressure/ } \\
\text { Normal blood pressure }\end{array}$ & $28 / 100$ & $30 / 100$ & $84.0^{\mathrm{a}}$ & 0.825 \\
\hline $\begin{array}{l}\text { Coronary heart disease/ } \\
\text { Non-coronary heart disease }\end{array}$ & $26 / 102$ & $27 / 103$ & $89.8^{\mathrm{a}}$ & 0.875 \\
\hline Smoker/Non-smoker & $48 / 80$ & $50 / 80$ & $82.8^{\mathrm{a}}$ & 0.923 \\
\hline Drinker/Non-drinker & $40 / 88$ & $43 / 87$ & $64.9^{\mathrm{a}}$ & 0.881 \\
\hline Educational years & $11.6 \pm 3.2$ & $10.9 \pm 4.1$ & $1.2^{\mathrm{b}}$ & 0.266 \\
\hline Left-handed/Right handed & $12 / 116$ & $14 / 116$ & $119.0^{\mathrm{a}}$ & 0.872 \\
\hline During of illness (years) & $9.9 \pm 6.6$ & - & - & - \\
\hline Pathological MRI (\%) & $77(60 \%)$ & - & - & - \\
\hline $\begin{array}{l}\text { Neuropsychological } \\
\text { impairment } \\
(2 \text { T-scores } 35)(\%)\end{array}$ & $90(70 \%)$ & - & - & - \\
\hline MMSE scores & $19.2 \pm 4.8$ & $29.6 \pm 2.6$ & $7.71^{b}$ & 0.001 \\
\hline CDR scale & & & - & - \\
\hline CDR 0 & 0 & 130 & & - \\
\hline CDR 0.5 & 60 & 0 & & - \\
\hline CDR 1 & 38 & 0 & & - \\
\hline $\mathrm{CDR} 2^{+}$ & 30 & 0 & & - \\
\hline
\end{tabular}

\subsection{The mRNA Levels of Serum Calreticulin in AD Patients and Healthy Subjects}

The quantitative RT-PCR results showed that the mRNA levels of serum calreticulin were lower in $\mathrm{AD}$ patients than those from healthy subjects. The mRNA levels of serum calreticulin were decreased in the AD patients from CDR 0.5 to $2^{+}$. The mRNA levels of serum calreticulin were the lowest in AD patients with CDR $2^{+}(p<0.05)$ (Figure 1). The serum mRNA levels were negatively associated with the progression of $\mathrm{AD}(p<0.01)$. 
Figure 1. Quantitative RT-PCR analysis for the calreticulin mRNA levels in serum of Alzheimer's disease (AD) patients and healthy participants. Quantitative RT-PCR analysis showed higher levels of calreticulin mRNA in healthy subjects than those in AD patients. Each bar represents the mean \pm S.D. of three independent experiments.

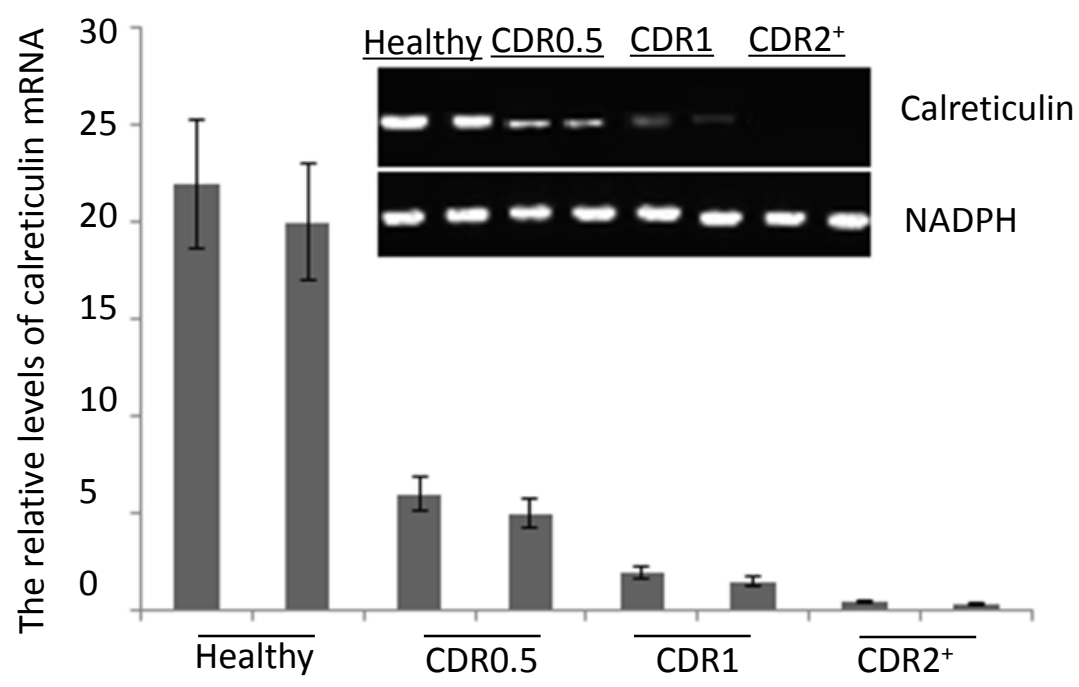

\subsection{ELISA Analysis}

The concentration of calreticulin in serum was measured using a standard curve (Figure 2A). The calreticulin concentrations were $400 \pm 200 \mathrm{ng} / \mathrm{mL}$ (95\% CI: 350-600 ng/mL) for healthy participants, $160 \pm 60 \mathrm{ng} / \mathrm{mL}(95 \% \mathrm{CI}: 110-180 \mathrm{ng} / \mathrm{mL})$ for AD patients with CDR 0.5, $80 \pm 25 \mathrm{ng} / \mathrm{mL}$ (95\% CI: 65-90 ng/mL) for AD patients with CDR 1 and $30 \pm 30 \mathrm{ng} / \mathrm{mL}(95 \% \mathrm{CI}: 20-60 \mathrm{ng} / \mathrm{mL})$ for AD patients with CDR $2^{+}$(Figure 2B). Just as for the above analyses, the serum protein levels of calreticulin were also negatively associated with the progression of $\mathrm{AD}(p<0.01)$.

Figure 2. Measurement of serum calreticulin using ELISA. (A) A standard curve was plotted between the concentration of calreticulin and absorbing value at $450 \mathrm{~nm}$ and (B) A bar diagram shows the differences in serum levels of calreticulin among AD patients with different Clinical Dementia Rating (CDR) scores.

A

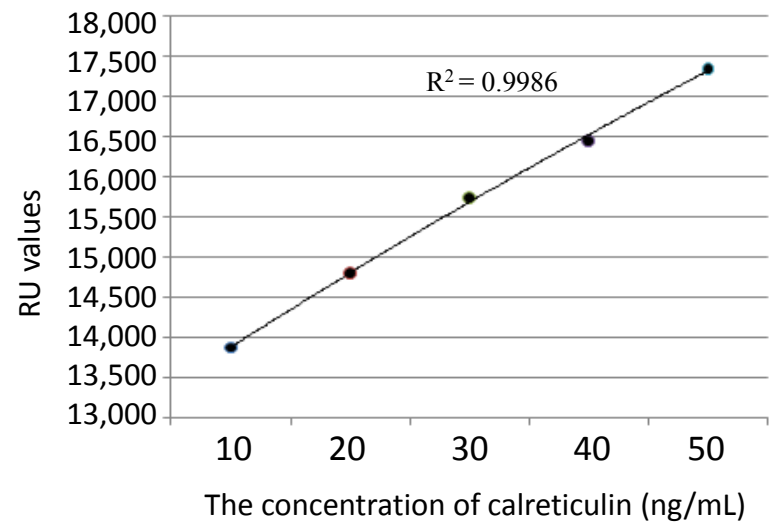

B

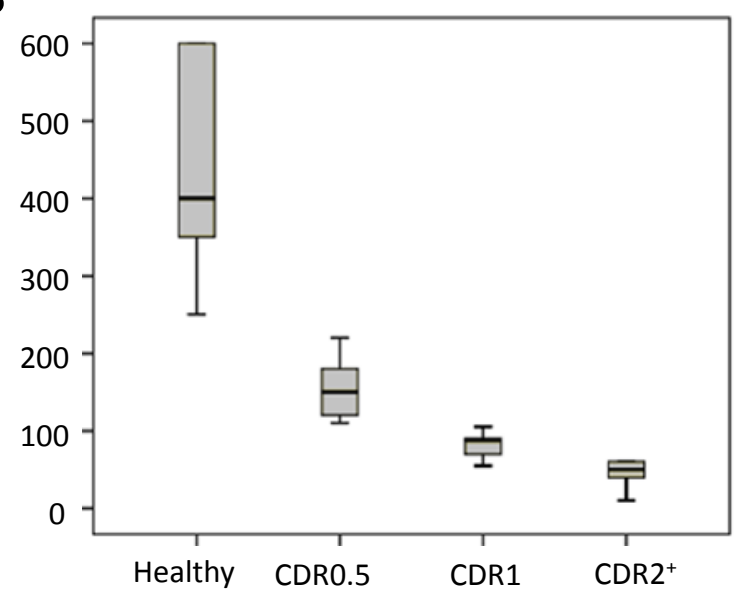




\subsection{Western Blot Analysis}

After concentrating serum and optimizing the separating process, Western Blot analysis of calreticulin in serum was successfully performed and indicated that the density band in $\mathrm{AD}$ participants was lower than that from healthy subjects (Figure 3A). The linearity of the sensitivity and specificity of the calreticulin antibody were showed in Figure 3B, which suggested that the experiments were conducted well. Just as the analysis of real-time PCR and ELISA, the serum levels of calreticulin were lower in AD patients than those in a healthy group and negatively associated with the progression of $\mathrm{AD}(p<0.01)$.

Figure 3. Western Blot analysis of serum calreticulin of AD patients and healthy subjects. (A) serum levels of calreticulin in AD patients and healthy subjects. Lane 1, a healthy control; Lanes 2-7, AD patients and (B) lanes 1-7, 0, 0.5, 1, 2, 4, 8 and $16 \mu \mathrm{g}$ of calreticulin was loaded in respectively. A band of approximately $55-\mathrm{kDa}$ protein could be detected (predicted molecular weight: $48 \mathrm{kDa}$ ).
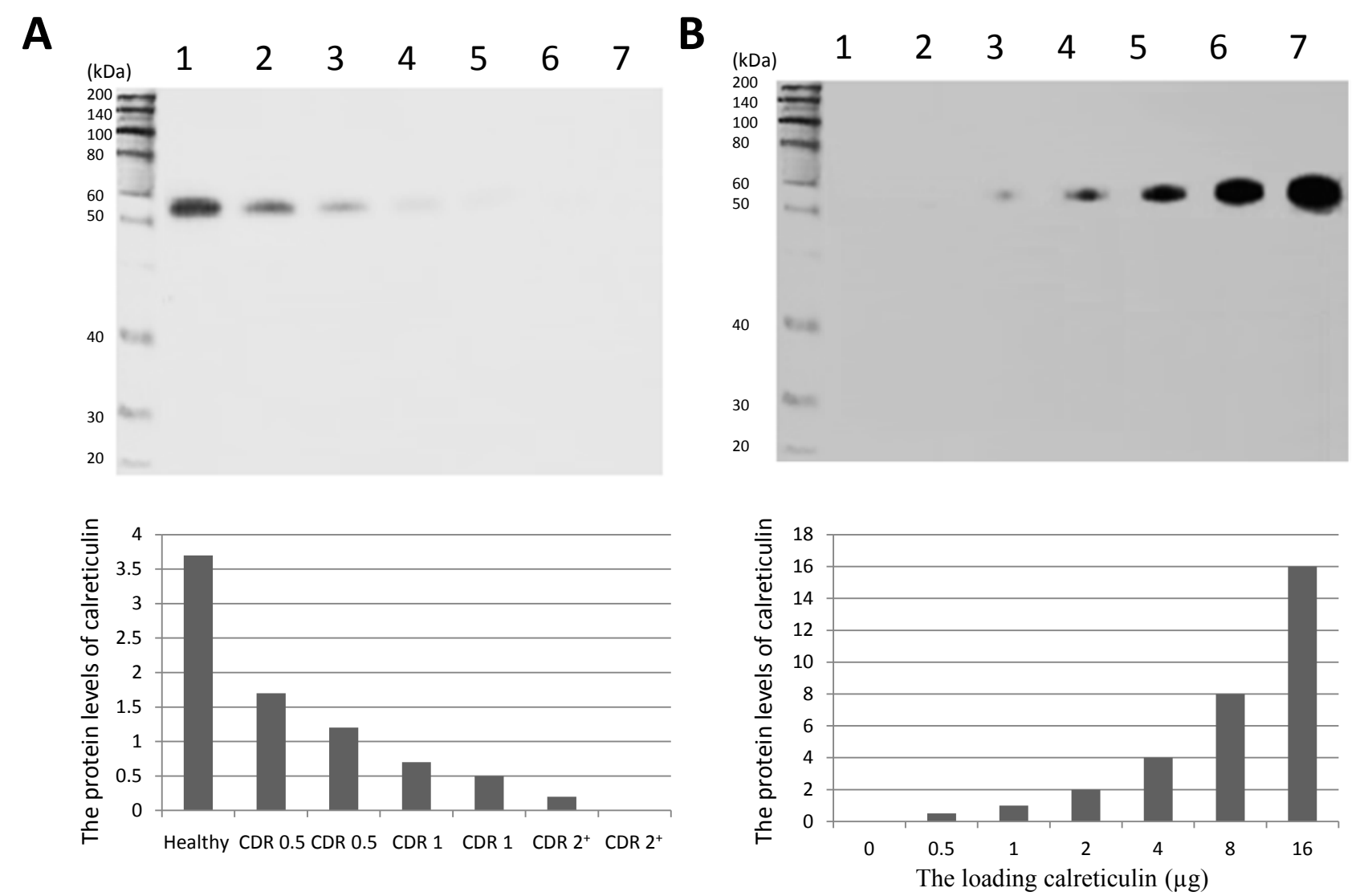

$\mathrm{AD}$ is a major health problem for ageing populations and is difficult to detect in an early stage. Prolonged nursing care and high cost are still needed because of the lack of a definitive therapy. AD is also a global health issue in rapidly ageing world, so it is a great challenge for dementia care. There have been more than 100 years since AD was reported in the early part of twentieth century [35]. In the past century, the technology keeping track of $\mathrm{AD}$ has been made a quite great progress. However, to date, the exact molecular mechanisms for degenerative changes in AD brain have not been clearly provided. AD can generally be detected after obvious changes in cognitive capacity, 
which leaves a little scope for reversal of these symptoms. Therefore, the normal therapeutic methods for $\mathrm{AD}$ remain far from satisfactory.

Ageing has been regarded as the highest risk factor for the development of AD. Progression in the prevalence of $\mathrm{AD}$ is doubled within every five to six years when patients are more than the age of 60 , which suggests that degenerative changes in the brain is accelerating in AD patients with ageing. Thus, anti-ageing interventions can be an effective therapeutic way for the prevention of $\mathrm{AD}$ in the elderly population. The experiments for the anti-ageing interventions have been widely reported in animal models and calorie restriction is regarded as the most effective way for prolonging lifespan by controlling age associated illnesses [36]. A previous report finds the relationship between immunosenescence and expression of antibodies to calreticulin [37], suggesting calreticulin is associated with the anti-aging activity in mammalians.

The role of calreticulin in the prevention of brain degeneration of $\mathrm{AD}$ has been reported. Calreticulin is a cell surface scavenger receptor and can interact with Abeta [21] while AD pathogenesis is generally believed to be driven by the production and deposition of Abeta [38]. The composition of these amyloid betas reflects different populations of amyloid deposits, which definitely correlates with the clinical status of AD. Imaging technologies make it possible to track amyloid pathology along with disease development of AD patients. Calreticulin plays an important role for prevention of progression of $\mathrm{AD}$ as a cell surface scavenger receptor and whose levels in $\mathrm{AD}$ brains are also found to be significantly lower than those in a healthy group [20].

The major issues for detection of $\mathrm{AD}$, particularly at early stages, remain a great challenge. Recently, serum biomarkers have drawn great attentions as an invasive diagnosis for AD [39-42]. However, to date, no data are available on calreticulin in the serum of $A D$, until the work conducted here. We found that down-regulation of serum calreticulin concentration was correlated with progression of $\mathrm{AD}$ according to $\mathrm{CDR}$ scores, which provided clinical relevance of the above observations in a Chinese population. The present study involved calreticulin was confirmed using the techniques, real-time qRT-PCR, ELISA and Western Blot. The study also demonstrated declining concentration of calreticulin in the blood of AD patients. Declined concentrations of calreticulin were most marked in AD patients and less marked in healthy subjects. Therefore, this difference of serum levels of calreticulin can be an indicator for an early diagnosis of AD.

Compared to other serum biomarkers of $\mathrm{AD}[15,16]$, calreticulin seems to be a more functional protein: (1) binding $\mathrm{Ca}^{2+}$ ions and regulating $\mathrm{Ca}^{2+}$ homeostasis [43]; (2) binding misfolded proteins [44]; (3) binding oligosaccharides [44]; (4) and regulation of some important signaling molecules so on [43]. The dysregulation of these functions can lead to the pathogenesis and development of AD [45-48]. For calreticulin, many new discoveries for its effects on AD will be revealed with further work. With more relevant results combining with the serum obtained by less invasive procedures, we hope that calreticulin will be widely used for the diagnosis of $\mathrm{AD}$ in the future. With current information, the specific role of calreticulin in $\mathrm{AD}$ is still unclear. However, some functions of calreticulin imply that calreticulin may be one of candidates related with the pathogenesis of AD. For example, as a $\mathrm{Ca}^{2+}$-sensor, calreticulin mediates $\mathrm{Ca}^{2+}$ homeostasis [49]. Interfering with $\mathrm{Ca}^{2+}$ permeability increases cerebral Abeta levels and promotes Abeta peptide deposition, which is an important risk factor for the late-onset of $\mathrm{AD}$ [50]. Calreticulin is a resident protein of the ER and reduced levels of calreticulin link ER stress and cell death in neurons [51], while ER stress can induce unfolded protein response and 
plays an important role in the pathogenesis of $\mathrm{AD}$ [52]. Furthermore, the neurons of $\mathrm{AD}$ patients are more susceptible to cell death [53] and elevated levels of calreticulin may prevent the progress of AD. The concentration of marker proteins can reflect physiological or pathological states associated with human health. We first detected the decreasing calreticulin in the serum of AD patients, which was consistent with the CDR scores. The values of serum concentrations of calreticulin were not affected by many parameters such as age and BMI.

Certainly, there are some limitations in the present work. For example, the work was not performed in a larger population, so it is necessary to conduct similar research in a larger population to increase the validity of the results. A total 258 participants were collected here including 128 AD patients and 130 healthy participants. The sample size seems a little small for the study of serum calreticulin. The main difficulty was caused by the fact that it was difficult to recruit more AD patients according to inclusion and exclusion criteria. On the other hand, many AD patients cast doubts on present techniques because AD could not be cured in most cases. Furthermore, a biomarker did not present a complete story of AD causality. In any case, the present work will be useful for better understanding the molecular mechanism for causing AD.

\section{Experimental Section}

\subsection{Participants}

All experiments were approved by the ethics committee from the Fourth Affiliated Hospital of China Medical University (Shenyang, China). A written informed consent was signed by all randomly recruited participants. From May 2010 to July 2013 a total of 128 patients were diagnosed for AD. AD patients were confirmed by screening cognitive impairment with Mini Mental State Examination (MMSE scores $\leq 24$ ) and a neuro-psychological test via Clinical Dementia Rating (CDR). All AD patients had an overall CDR of 0.5 or over 0.5 . AD patients were diagnosed according to NINCDS-ADRDA criteria [54]. To further diagnose AD based on imaging-based techniques, the magnetic resonance image (MRI) relaxation time constant was examined in the brains of $\mathrm{AD}$ patients according to a previous report [55]. Neuropsychological impairment was measured according to Global Deficit Score (GDS) for classifying Neuropsychological impairment [56]. A total of 130 elderly healthy individuals (MMSE scores $>28, \mathrm{CDR}=0$ ) were randomly recruited as controls. All healthy subjects had no brain diseases with the assessment of the MRI and CT. Meanwhile, they had no history or symptoms of ischemic or hemorrhagic stroke.

All the persons including AD patients and healthy participants were unrelated ethnic Han Chinese. All the subjects shared a similar cultural and economic background. All subjects were randomly recruited from the same place with healthy livers and kidneys. Other parameters, such as blood pressure, pulmonary function, electrocardiography and chest radiography were in fine results in all subjects. AD is affected by age, gender, education level, BMI (body mass index) and life habits (smoking and drinking) so on. Thus, all these parameters were constrained to keep no heterogeneous results between $\mathrm{AD}$ patients and healthy subjects. 


\section{2. $m R N A$ Extraction}

Five milliliters of venous blood was taken from each individual. The serum was collected after centrifugation of venous blood at $3000 \times \mathrm{g}$ for $10 \mathrm{~min}$. Total RNA was extracted from $1 \mathrm{~mL}$ serum using the serum RNA extraction kit (2BScientific Ltd., Upper Heyford, UK).

\subsection{Real-Time $q R T-P C R$}

One microliter of mRNA was reverse-transcribed into cDNA in a $10 \mu \mathrm{L}$ total volume using AMV reverse transcriptase (TaKaRa Biotechnology (Dalian) Co., Ltd., Dalian, China). Five microliter from the reverse-transcribed mixture were amplified by real-time qPCR in a $20 \mu \mathrm{L}$ volume with primers for calreticulin (Forward primer, 5'-aggatgatgagtttacacac-3'; Reverse primer, 5'-tcatcgatcttggcccgctc-3') and GAPDH (Forward primer, 5'-tcaagatcatcagcaatgcc-3'; Reverse primer, 5'-gaccttgcccacagccttgg-3'). PCR was performed using LightCycler ${ }^{\circledR}$ FastStart DNA Master SYBR Green I with qTOWER 2.0 (Analytik Jena, Jena, Germany). The PCR condition was designed as 40 cycles of denaturing $\left(95{ }^{\circ} \mathrm{C}\right.$ for $5 \mathrm{~s})$, annealing $\left(60{ }^{\circ} \mathrm{C}\right.$ for $\left.5 \mathrm{~s}\right)$ and extension $\left(72{ }^{\circ} \mathrm{C}\right.$ for $\left.15 \mathrm{~s}\right)$. To control the integrity between the sample and inter-sample in mRNA level, GAPDH gene was amplified under the same condition.

\subsection{ELISA}

Microtiter plates were coated with serum sample in each well with the same volume and ELISA was performed by using ELISA Kit for calreticulin (CRT) according to an instruction manual (SEB486Hu, Uscn Life Science Inc., Wuhan, China). The absorption value for Nitrophenolate 158 was measured at $405 \mathrm{~nm}$ using Automated ELISA analyzer (Yantai Addcare Bio-Tech Co., Ltd., Yantai, China). The series of different concentrations of calreticulin were used to plot a standard curve.

\subsection{Western Blot}

To confirm the existence of calreticulin in serum, serum samples from AD patients and controls were prepared in high quality via the removal of interfering proteins using Multiple Affinity Removal Spin Cartridge (Agilent Technologies, Santa Clara, CA, USA). The fluid was concentrated using centricon column with a $30-\mathrm{kDa}$ cutoff value (Millipore, Billerica, MA, USA). The concentration of total proteins was determined using BCA protein quantification kit (Pierce, Rockford, IL, USA). Western Blot was conducted using Calreticulin Antibody (1:1000) (MA5-15382, Thermo Fisher Scientific Inc., Rockford, IL, USA) and goat anti-mouse IgG-HRP (sc-2005, Santa Cruz Biotechnology, Santa Cruz, CA, USA). Immunoreactive bands were measured by ECL (GE Healthcare, Beijing, China) and densitometry was quantified using Image J software 1.45 (NIH, Bethesda, MD, USA).

\subsection{Statistical Analysis}

All the variables in serum between AD patients and healthy subjects were compared using a $t$-test. $p<0.05$ was considered statistically significant. 


\section{Conclusions}

We find a decrease of serum levels of calreticulin in AD patients, which can predict the progression of AD in patients. Serum levels of calreticulin can be a negative biomarker for early diagnosis of AD. Further research to determine the molecular mechanisms whether calreticulin prevents the development of $\mathrm{AD}$ in a larger population is much needed. Based on all the work, an effective therapeutic method can be developed for the therapy of AD.

\section{Acknowledgments}

We would like to express our gratitude to all three anonymous reviewers who provided us with valuable comments that clearly improved our paper.

\section{Author Contributions}

Qiao Lin contributed to the experiments design and wrote the manuscript. Yunpeng Cao contributed to the acquisition of data, technical support and revised the manuscript. Jie Gao contributed to the analysis and interpretation of the manuscript.

\section{Conflicts of Interest}

The authors declare no conflict of interest.

\section{References}

1. Mayeux, R.; Stern, Y. Epidemiology of Alzheimer disease. Cold Spring Harb. Perspect. Med. 2012, 2, doi:10.1101/cshperspect.a006239.

2. Guzman-Velez, E.; Feinstein, J.S.; Tranel, D. Feelings without memory in Alzheimer disease. Cogn. Behav. Neurol. 2014, 27, 117-129.

3. Takeda, S.; Sato, N.; Morishita, R. Systemic inflammation, blood-brain barrier vulnerability and cognitive/non-cognitive symptoms in Alzheimer disease: Relevance to pathogenesis and therapy. Front. Aging Neurosci. 2014, 6, 171.

4. Malkki, H. Alzheimer disease: Effects of the APOE epsilon4 allele on brain development. Nat. Rev. Neurol. 2014, 10, 4.

5. Rassas, A.A.; Mrabet Khiari, H.; Hadj Fredj, S.; Sahnoun, S.; Batti, H.; Zakraoui, N.O.; Cherif, A.; Anane, N.; Ben Ali, N.; Messaoud, T.; et al. High APOE epsilon 4 allele frequencies associated with Alzheimer disease in a Tunisian population. Neurol. Sci. 2012, 33, 33-37.

6. Redwine, L.; Mills, P.J.; Sada, M.; Dimsdale, J.; Patterson, T.; Grant, I. Differential immune cell chemotaxis responses to acute psychological stress in Alzheimer caregivers compared to non-caregiver controls. Psychosom. Med. 2004, 66, 770-775.

7. Kuehn, B.M. Anesthesia-Alzheimer disease link probed. JAMA 2007, 297, 1760.

8. Burns, C.M.; Chen, K.; Kaszniak, A.W.; Lee, W.; Alexander, G.E.; Bandy, D.; Fleisher, A.S.; Caselli, R.J.; Reiman, E.M. Higher serum glucose levels are associated with cerebral hypometabolism in Alzheimer regions. Neurology 2013, 80, 1557-1564. 
9. Wainaina, M.N.; Chen, Z.; Zhong, C. Environmental factors in the development and progression of late-onset Alzheimer's disease. Neurosci. Bull. 2014, 30, 253-270.

10. Serrano-Pozo, A.; Qian, J.; Monsell, S.E.; Frosch, M.P.; Betensky, R.A.; Hyman, B.T. Examination of the clinicopathologic continuum of Alzheimer disease in the autopsy cohort of the National Alzheimer Coordinating Center. J. Neuropathol. Exp. Neurol. 2013, 72, 1182-1192.

11. Blennow, K.; Hampel, H. CSF markers for incipient Alzheimer's disease. Lancet Neurol. 2003, 2, 605-613.

12. Dubois, B.; Feldman, H.H.; Jacova, C.; Dekosky, S.T.; Barberger-Gateau, P.; Cummings, J.; Delocourte, A.; Galasko, D.; Gauthier, S.; Jicha, G.; et al. Research criteria for the diagnosis of Alzheimer's disease: Revising the NINCDS-ADRDA criteria. Lancet Neurol. 2007, 6, 734-746.

13. Afshari, F.M.; Rajput, A. How to interpret a blood contaminated traumatic spinal tap? Neurology 2010, 74, A211-A211.

14. Watabe-Rudolph, M.; Song, Z.; Lausser, L.; Schnack, C.; Begus-Nahrmann, Y.; Scheithauer, M.O.; Rettinger, G.; Otto, M.; Tumani, H.; Thal, D.R.; et al. Chitinase enzyme activity in CSF is a powerful biomarker of Alzheimer disease. Neurology 2012, 78, 569-577.

15. Trueba-Saiz, A.; Cavada, C.; Fernandez, A.M.; Leon, T.; Gonzalez, D.A.; Fortea Ormaechea, J.; Lleo, A.; del Ser, T.; Nunez, A.; Torres-Aleman, I. Loss of serum IGF-I input to the brain as an early biomarker of disease onset in Alzheimer mice. Transl. Psychiatry 2013, 3, e330.

16. Yang, M.H.; Yang, Y.H.; Lu, C.Y.; Jong, S.B.; Chen, L.J.; Lin, Y.F.; Wu, S.J.; Chu, P.Y.; Chung, T.W.; Tyan, Y.C. Activity-dependent neuroprotector homeobox protein: A candidate protein identified in serum as diagnostic biomarker for Alzheimer's disease. J. Proteomics 2012, $75,3617-3629$.

17. Ranford, J.C.; Coates, A.R.; Henderson, B. Chaperonins are cell-signalling proteins: The unfolding biology of molecular chaperones. Expert Rev. Mol. Med. 2000, 2, 1-17.

18. Dubois, B.; Feldman, H.H.; Jacova, C.; Cummings, J.L.; Dekosky, S.T.; Barberger-Gateau, P.; Delacourte, A.; Frisoni, G.; Fox, N.C.; Galasko, D.; et al. Revising the definition of Alzheimer's disease: A new lexicon. Lancet Neurol. 2010, 9, 1118-1127.

19. Dey, S.; Matsunami, H. Calreticulin chaperones regulate functional expression of vomeronasal type 2 pheromone receptors. Proc. Natl. Acad. Sci. USA 2011, 108, 16651-16656.

20. Taguchi, J.; Fujii, A.; Fujino, Y.; Tsujioka, Y.; Takahashi, M.; Tsuboi, Y.; Wada, I.; Yamada, T. Different expression of calreticulin and immunoglobulin binding protein in Alzheimer's disease brain. Acta Neuropathol. 2000, 100, 153-160.

21. Duus, K.; Hansen, P.R.; Houen, G. Interaction of calreticulin with amyloid beta peptide 1-42. Protein Pept. Lett. 2008, 15, 103-107.

22. Hanenberg, M.; McAfoose, J.; Kulic, L.; Welt, T.; Wirth, F.; Parizek, P.; Strobel, L.; Cattepoel, S.; Spani, C.; Derungs, R.; et al. Amyloid-beta peptide-specific DARPins as a novel class of potential therapeutics for Alzheimer disease. J. Biol. Chem. 2014, 289, 27080-27089.

23. Besser, L.M.; Gill, D.P.; Monsell, S.E.; Brenowitz, W.; Meranus, D.H.; Kukull, W.; Gustafson, D.R. Body mass index, weight change, and clinical progression in mild cognitive impairment and Alzheimer disease. Alzheimer Dis. Assoc. Disord. 2014, 28, 36-43.

24. Vidoni, E.D.; Townley, R.A.; Honea, R.A.; Burns, J.M.; Alzheimer's Disease Neuroimaging, I. Alzheimer disease biomarkers are associated with body mass index. Neurology 2011, 77, 1913-1920. 
25. Sebastiao, I.; Candeias, E.; Santos, M.S.; de Oliveira, C.R.; Moreira, P.I.; Duarte, A.I. Insulin as a bridge between type 2 diabetes and alzheimer disease-How anti-diabetics could be a solution for dementia. Front. Endocrinol. (Lausanne) 2014, 5, 110.

26. Butterfield, D.A.; di Domenico, F.; Barone, E. Elevated risk of type 2 diabetes for development of Alzheimer disease: A key role for oxidative stress in brain. Biochim. Biophys. Acta 2014, 1842, 1693-1706.

27. Kivipelto, M.; Helkala, E.L.; Laakso, M.P.; Hanninen, T.; Hallikainen, M.; Alhainen, K.; Iivonen, S.; Mannermaa, A.; Tuomilehto, J.; Nissinen, A.; et al. Apolipoprotein E epsilon4 allele, elevated midlife total cholesterol level, and high midlife systolic blood pressure are independent risk factors for late-life Alzheimer disease. Ann. Intern. Med. 2002, 137, 149-155.

28. Arlt, S.; Kontush, A.; Muller-Thomsen, T.; Beisiegel, U. Lipid peroxidation as a common pathomechanism in coronary heart disease and Alzheimer disease. Z. Gerontol .Geriatr. 2001, 34, 461-465.

29. Almeida, O.P.; Garrido, G.J.; Lautenschlager, N.T.; Hulse, G.K.; Jamrozik, K.; Flicker, L. Smoking is associated with reduced cortical regional gray matter density in brain regions associated with incipient Alzheimer disease. Am. J. Geriatr. Psychiatry 2008, 16, 92-98.

30. Wiscott, R.; Kopera-Frye, K.; Seifert, L. Possible consequences of social drinking in the early stages of Alzheimer disease. Geriatr. Nurs. 2001, 22, 100-104.

31. Marinho, V.; Laks, J.; Engelhardt, E.; Conn, D. Alcohol abuse in an elderly woman taking donepezil for Alzheimer disease. J. Clin. Psychopharmacol. 2006, 26, 683-685.

32. Pradier, C.; Sakarovitch, C.; Le Duff, F.; Layese, R.; Metelkina, A.; Anthony, S.; Tifratene, K.; Robert, P. The mini mental state examination at the time of Alzheimer's disease and related disorders diagnosis, according to age, education, gender and place of residence: A cross-sectional study among the French National Alzheimer database. PLoS One 2014, 9, e103630.

33. Roe, C.M.; Mintun, M.A.; D’Angelo, G.; Xiong, C.; Grant, E.A.; Morris, J.C. Alzheimer disease and cognitive reserve: Variation of education effect with carbon 11-labeled Pittsburgh Compound B uptake. Arch. Neurol. 2008, 65, 1467-1471.

34. De Leon, M.J.; la Regina, M.E.; Ferris, S.H.; Gentes, C.I.; Miller, J.D. Reduced incidence of left-handedness in clinically diagnosed dementia of the Alzheimer type. Neurobiol. Aging 1986, 7, 161-164.

35. Stoddart, W.H. Presbyophrenia (Alzheimer's disease). Proc. R. Soc. Med. 1913, 6, 13-14.

36. Kemnitz, J.W. Calorie restriction and aging in nonhuman primates. ILAR J. 2011, 52, 66-77.

37. Higashino, A.; Kageyama, T.; Kantha, S.S.; Terao, K. Detection of elevated antibody against calreticulin by ELISA in aged cynomolgus monkey plasma. Zool. Sci. 2011, 28, 85-89.

38. Luo, J.; Warmlander, S.K.; Graslund, A.; Abrahams, J.P. Non-chaperone proteins can inhibit aggregation and cytotoxicity of Alzheimer amyloid beta peptide. J. Biol. Chem. 2014, 289, 27766-27775.

39. Bernard, A. Elevated serum DDE and risk for Alzheimer disease. JAMA Neurol. 2014, 71, 1055-1056.

40. Squitti, R.; Ghidoni, R.; Siotto, M.; Ventriglia, M.; Benussi, L.; Paterlini, A.; Magri, M.; Binetti, G.; Cassetta, E.; Caprara, D.; et al. Value of serum nonceruloplasmin copper for prediction of mild cognitive impairment conversion to Alzheimer disease. Ann. Neurol. 2014, 75, 574-580. 
41. Bible, E. Alzheimer disease: High serum levels of the pesticide metabolite DDE-A potential environmental risk factor for Alzheimer disease. Nat. Rev. Neurol. 2014, 10, 125.

42. Richardson, J.R.; Roy, A.; Shalat, S.L.; von Stein, R.T.; Hossain, M.M.; Buckley, B.; Gearing, M.; Levey, A.I.; German, D.C. Elevated serum pesticide levels and risk for Alzheimer disease. JAMA Neurol. 2014, 71, 284-290.

43. Zimmerman, K.A.; Graham, L.V.; Pallero, M.A.; Murphy-Ullrich, J.E. Calreticulin regulates transforming growth factor-beta-stimulated extracellular matrix production. J. Biol. Chem. 2013, $288,14584-14598$.

44. Thomson, S.P.; Williams, D.B. Delineation of the lectin site of the molecular chaperone calreticulin. Cell Stress Chaperones 2005, 10, 242-251.

45. Bosco, P.; Ferri, R.; Salluzzo, M.G.; Castellano, S.; Signorelli, M.; Nicoletti, F.; Nuovo, S.D.; Drago, F.; Caraci, F. Role of the transforming-growth-factor-betal gene in late-onset Alzheimer's disease: Implications for the treatment. Curr. Genomics 2013, 14, 147-156.

46. Li, J.Q.; Yu, J.T.; Jiang, T.; Tan, L. Endoplasmic reticulum dysfunction in Alzheimer's disease. Mol. Neurobiol. 2014, doi:10.1007/s12035-014-8695-8.

47. Schworer, R.; Zubkova, O.V.; Turnbull, J.E.; Tyler, P.C. Synthesis of a targeted library of heparan sulfate hexa- to dodecasaccharides as inhibitors of beta-secretase: Potential therapeutics for Alzheimer's disease. Chemistry 2013, 19, 6817-6823.

48. Walton, J.R. Aluminum disruption of calcium homeostasis and signal transduction resembles change that occurs in aging and Alzheimer's disease. J. Alzheimers Dis. 2012, 29, 255-273.

49. Bibi, A.; Agarwal, N.K.; Dihazi, G.H.; Eltoweissy, M.; van Nguyen, P.; Mueller, G.A.; Dihazi, H. Calreticulin is crucial for calcium homeostasis mediated adaptation and survival of thick ascending limb of Henle's loop cells under osmotic stress. Int. J. Biochem. Cell Biol. 2011, 43, 1187-1197.

50. Dreses-Werringloer, U.; Lambert, J.C.; Vingtdeux, V.; Zhao, H.; Vais, H.; Siebert, A.; Jain, A.; Koppel, J.; Rovelet-Lecrux, A.; Hannequin, D.; et al. A polymorphism in CALHM1 influences $\mathrm{Ca}^{2+}$ homeostasis, Abeta levels, and Alzheimer's disease risk. Cell 2008, 133, 1149-1161.

51. Bernard-Marissal, N.; Moumen, A.; Sunyach, C.; Pellegrino, C.; Dudley, K.; Henderson, C.E.; Raoul, C.; Pettmann, B. Reduced calreticulin levels link endoplasmic reticulum stress and Fas-triggered cell death in motoneurons vulnerable to ALS. J. Neurosci. 2012, 32, 4901-4912.

52. Huang, H.C.; Tang, D.; Lu, S.Y.; Jiang, Z.F. Endoplasmic reticulum stress as a novel neuronal mediator in Alzheimer's disease. Neurol. Res. 2014, doi:10.1179/1743132814Y.0000000448.

53. Duan, L.; Bhattacharyya, B.J.; Belmadani, A.; Pan, L.; Miller, R.J.; Kessler, J.A. Stem cell derived basal forebrain cholinergic neurons from Alzheimer's disease patients are more susceptible to cell death. Mol. Neurodegener. 2014, 9, 3.

54. Tamaoka, A. Alzheimer's disease: Definition and National Institute of Neurological and Communicative Disorders and Stroke and the Alzheimer's Disease and Related Disorders Association (NINCDS-ADRDA). Nihon Rinsho 2011, 69, 240-245. 
55. Haris, M.; Singh, A.; Cai, K.; McArdle, E.; Fenty, M.; Davatzikos, C.; Trojanowski, J.Q.; Melhem, E.R.; Clark, C.M.; Borthakur, A. T(1rho) MRI in Alzheimer's disease: Detection of pathological changes in medial temporal lobe. J. Neuroimaging 2011, 21, e86-90.

56. Reichenberg, A.; Harvey, P.D.; Bowie, C.R.; Mojtabai, R.; Rabinowitz, J.; Heaton, R.K.; Bromet, E. Neuropsychological function and dysfunction in schizophrenia and psychotic affective disorders. Schizophr. Bull. 2009, 35, 1022-1029.

(C) 2014 by the authors; licensee MDPI, Basel, Switzerland. This article is an open access article distributed under the terms and conditions of the Creative Commons Attribution license (http://creativecommons.org/licenses/by/4.0/). 